\title{
соцИОЛОГИЯ Здоровья
}

DOI: 10.14515/monitoring.2020.2.742

\section{Правильная ссылка на статью:}

Дудина В.И., Руппель А. Ф. "Меня выводит из себя любая мелочь»: самомедикализация стресса и паттерны употребления фармацевтических препаратов в цифровом обществе // Мониторинг общественного мнения: экономические и социальные перемены. 2020. № 2 . C. 312-330. https://doi.org/10.14515/monitoring.2020.2.742.

\section{For citation:}

Dudina V.I., Ruppel A. F. (2020) “Every little thing makes me mad”: self-medicalization of stress and the patterns of taking pharmaceuticals in a digital society. Monitoring of Public Opinion: Economic and Social Changes. No. 2. P. 312-330. https://doi.org/10.14515/monitoring.2020.2.742.
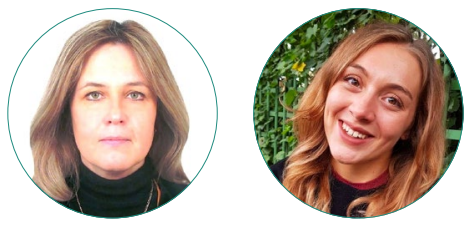

В. И. Дудина, А. Ф. Руппель "МЕНЯ ВЫВОДИТ ИЗ СЕБЯ ЛЮБАЯ МЕЛОЧЬ": САМОМЕДИКАЛИЗАЦИЯ СТРЕССА И ПАТТЕРНЫ УПОТРЕБЛЕНИЯ ФАРМАЦЕВТИЧЕСКИХ ПРЕПАРАТОВ В ЦИФРОВОМ ОБЩЕСТВЕ

\section{«МЕНЯ ВЫВОДИТ ИЗ СЕБЯ ЛЮБАЯ МЕЛОЧЬ": САМОМЕДИКАЛИЗАЦИЯ СТРЕССА И ПАТТЕРНЫ УПОТРЕБЛЕНИЯ ФАРМАЦЕВТИЧЕСКИХ ПРЕПАРАТОВ В ЦИФРОВОМ ОБЩЕСТВЕ}

ДУДИНА Виктория Ивановна - доктор социологических наук, доцент, зав. кафедрой прикладной и отраслевой социологии, Санкт-Петербургский государственный университет, СанктПетербург, Россия E-MAIL:v.dudina@spbu.ru https://orcid.org/0000-0003-2099-2345

\begin{abstract}
“EVERY LITTLE THING MAKES ME MAD”: SELF-MEDICALIZATION OF STRESS AND THE PATTERNS OF TAKING PHARMACEUTICALS IN A DIGITAL SOCIETY
\end{abstract}

Victoria I. DUDINA ${ }^{1}-D r$. Sci. (Soc.), Associate Professor, Chair of the Department of Applied Sociology E-MAIL:v.dudina@spbu.ru https://orcid.org/0000-0003-2099-2345

\footnotetext{
1 St. Petersburg State University, St. Petersburg, Russia
} 
РУППЕЛЬ Анастасия Фридриховна магистр социологии, менеджер проектов направления "Социальные исследования", Региональная общественная организация социальных проектов в сфере благополучия населения "Стеллит", Санкт-Петербург, Россия

E-MAIL: anastasija.ruppel@gmail.com https://orcid.org/0000-0002-2074-0255

Аннотация. Практики борьбы со стрессом и его последствиями в современном обществе все больше опираются на прием фармацевтических препаратов. В самомедикализации стресса, когда человек сам диагностирует симптомы и наделяет их статусом болезни, требующей применения медикаментов, большую роль играют интернет-ресурсы, где пользователи могут обсуждать особенности различных лекарственных препаратов. Цель исследования состоит в том, чтобы выявить типичные особенности самомедикализации стресса через изучение дискуссий пользователей интернета, обсуждающих медикаментозные способы управления стрессом. В выборку было включено 13 интернет-ресурсов, посвященных обсуждению применения фармацевтических препаратов для управления стрессом, содержащих в общей сложности 762 комментария. В результате индуктивного и дедуктивного кодирования комментариев пользователей были выделены три паттерна употребления фармацевтических препаратов: самоназначение фармацевтических препаратов, употребление фармацевтических препаратов как дополнительный способ избавления от стресса, употребление фармацевтических препаратов по назначению врача. Выделенные паттерны различаются по степени самомеди-
Anastasia F. RUPPEL ${ }^{2}$ - Master of Sociology, Social Research Project Manager E-MAIL: anastasija.ruppel@gmail.com https://orcid.org/0000-0002-2074-0255

\footnotetext{
2 Regional Public Organization of Social Projects for Population's Well-Being (NGO “Stellit”), St. Petersburg, Russia
}

Abstract. Patterns of coping with stress and its consequences in the modern society increasingly rely on pharmaceutical drugs. In self-medicalization, implying self-diagnosis of symptoms qualified as a disease which needs to be treated medically, a big role is played by online resources where users can discuss the specifics of various medicines. The purpose of the study is to reveal the features of stress self-medicalization by studying the comments of the users discussing pharmacological treatment of stress. The sample included 13 Internet resources (a total of 762 comments) devoted to the use of medications to handle stress. As a result of inductive and deductive coding of user comments three patterns of medication use were singled out: (1) self-prescribed medication, (2) use of medicines as an additional way to relieve stress, (3) use of prescription medicines. These patterns differ in the level of stress self-medicalization and help to understand the extent to which people affected by this problem are capable of solving this problem by themselves, using only online user comments, as well as to detect the situations where they need a professional medical advice. 
кализации стресса и позволяют понять, насколько люди, которых затронула данная проблема, склонны решать ее самостоятельно с привлечением советов пользователей интернета, и в каких ситуациях они выбирают профессиональную медицинскую помощь.

Ключевые слова: медикализация, самомедикализация, стресс, социология здоровья, интернет, социальные медиа, фармацевтические препараты

Благодарность. Исследование выполнено при финансовой поддержке РФФИ в рамках научного проекта № 18013-00726.
Keywords: medicalization, self-medicalization, stress, sociology of health, Internet, social media, pharmaceuticals

Acknowledgments. The study is financed by Russian Foundation for Basic Research under project no. 18-013-00726.

Хронический стресс, неврозы и тревожность стали отличительными явлениями нашего времени. В 2013 г. Европейское агентство по безопасности и гигиене труда пришло к выводу, что стресс, связанный с работой, является одной из самых серьезных проблем в сфере охраны труда, которая затрагивает 51 \% работников из 33 стран EC ${ }^{1}$. В соответствии с этими результатами Всемирная организация здравоохранения заявила, что стресс является эпидемией XXI в., а количество людей, страдающих от стресса, вызванного работой, скорее всего, увеличится [Väänänen, Murray, Kuokkanen, 2014: 117].

В России изучать распространенность стресса в повседневной жизни начали относительно недавно. По данным опроса "Левада-Центра", проведенного в 2017 г., ${ }^{2}$ $72 \%$ опрошенных испытывают стресс, при этом 39\% испытывают стресс несколько раз в месяц, $22 \%$ - несколько раз в неделю и $11 \%$ - почти ежедневно. Согласно исследованию ВЦИОМ 2017 г., на состояние здоровья россиян больше всего влияют стресс и эмоциональное состояние: 32 \% опрошенных выбрали именно эту причину, тогда как такие факторы, как доступность квалифицированной медицинской помощи и доступность качественных лекарственных средств назвали только $24 \%$ и $11 \%$ респондентов соответственно ${ }^{3}$. Кросс-культурное сравнительное исследование стрессоустойчивости россиян, американцев и тайваньцев [Glei et. al., 2013] показало, что в России уровень воспринимаемого стресса был самым высоким. Факторами, повлиявшими на высокий уровень стресса, по мнению

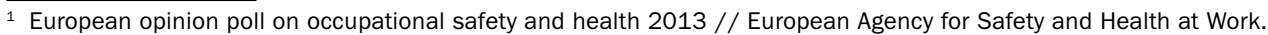
Электронный ресурc]. URL: https://osha.europa.eu/en/surveys-and-statistics-osh/european-opinion-polls-safety-andhealth-work/european-opinion-poll-occupational-safety-and-health-2013 (дата обращения: 10.07.2019).

2 Напряжение и стресс [Электронный ресурс] // Левада-Центр. 15.09.2017. URL: https://www.levada.ru/2017/09/15/ napryazhenie-i-stress/ (дата обращения: 01.04.2020).

3 Россия-2017: качество жизни [Электронный ресурс] // ВцИОМ. 23.10.2017. URL: https://wciom.ru/index.php?id= 236\&uid=116472 (дата обращения: 01.04.2020).
} 
исследователей, стали социальные и экономические изменения, нестабильность, рост неравенства. В исследованиях российских авторов стресс рассматривается как фактор риска здоровью населения и распространения вредных привычек [Бухтияров, 2016; Короленко, 2019; Шафиркин, 2013]. Исследуются особенности преодоления стресса у различных групп населения [Имамгалиева 2017; Давыдова, Козьмина, 2014; Зотова, Зотов, 2015; Сабадаш, 2016].

Практики совладания со стрессом в современном обществе в значительной мере опираются на прием фармацевтических препаратов. В исследовании центра HeadHunter было выявлено, что $18 \%$ респондентов принимают успокоительные препараты и $3 \%$ - антидепрессанты. В качестве основных причин приема препаратов (при условии выбора нескольких вариантов ответа) опрошенные назвали: ссоры с начальством или коллегами (59\%), чрезмерно большой объем выполняемой работы (49\%), недовольство работой (31\%), слишком быстрый темп работы $(25 \%)^{4}$. В опросе "Левада-Центра" 2017 г. в приеме медикаментов для борьбы с последствиями стресса признались $7 \%$ опрошенных ${ }^{5}$. Согласно опросу Фонда общественного мнения (ФОМ) 2018 г., успокоительные средства постоянно находятся в аптечке у $48 \%$ респондентов ${ }^{6}$.

Успокоительные часто принимаются в рамках самостоятельного лечения, когда люди сами назначают себе препараты, без консультации со специалистами. В России практика самолечения распространена достаточно широко. Согласно исследованиям, проведенным ФОМ в 2015 г., людей, предпочитающих лечиться самостоятельно, было $46 \%{ }^{7}$, а в 2017 г. таких респондентов стало уже $63 \%{ }^{8}$. По данным опроса ВЦИОМ 2017 г., занимаются самолечением $35 \%$ опрошенных 9 . В опросе ФОМ в качестве основных причин самостоятельного лечения респонденты указали на недоверие официальной медицине (14\%) и недоступность медицинской помощи по финансовым или организационным причинам (14\%), а 4 \% опрошенных отметили, что и так знают все о своем заболевании ${ }^{10}$.

В российской медицине долгое время господствовала патерналистская концепция, согласно которой подчинение профессиональному знанию рассматривалось в качестве высшей добродетели “правильного" пациента, а любые попытки обходиться без врачебной помощи считались потенциально опасными. В настоящее время происходит постепенный переход к партисипаторной медицине, когда за пациентом признается право иметь обоснованные суждения относительно

\footnotetext{
${ }_{4}^{4}$ Самые стрессовые профессии [Электронный ресурс] // HeadHunter. URL: https://spb.hh.ru/article/14948 (дата обращения: 01.04.2020).

5 Напряжение и стресс [Электронный ресурс] // Левада-Центр. 15.09.2017. URL: https://www.levada.ru/2017/09/15/ napryazhenie-i-stress/ (дата обращения: 01.04.2020).

${ }^{6}$ Домашняя аптечка [Электронный ресурс] // ФОМ. 27.02.2018. URL: http://fom.ru/Zdorove/13970 (дата обращения: 01.04.2020).

7 Как россияне лечатся [Электронный ресурс] // ФОМ. 15.10.2015. URL: http://fom.ru/Zdorove-i-sport/12348 (дата обращения: 01.04.2020).

8 Образ жизни и здоровье [Электронный ресурс] // ФОМ. 12.12.2017. URL: http://fom.ru/Zdorove-i-sport/13883 (дата обращения: 01.04.2020).

9 Национальный мониторинг здоровья россиян [Электронный ресурс] // ВЦИОМ. 11.05.2017. URL: https://wciom. ru/index.php?id=236\&uid=116194 (дата обращения: 01.04.2020).

${ }^{10}$ Как россияне лечатся [Электронный ресурс] // ФОМ. 15.10.2015. URL: http://fom.ru/Zdorove-i-sport/12348 (дата обращения: 01.04.2020).
} 
своего собственного здоровья и лечения. Концепция партисипаторной медицины и "самоменеджмента"заболеваний признает, что человек без специального медицинского образования может принимать ответственные и обоснованные решения на основании информации, полученной как от лечащего врача, так и из дополнительных источников [Leventhal, Phillips, Burns, 2016; Grady, Gough, 2014]. Концепция "ответственного самолечения", или самопомощи (self care), разработанная Всемирной организацией здравоохранения (В03), предполагает, что люди, обладающие адекватными знаниями и ответственностью, могут сами заботиться о своем здоровье [Толпыгина и др., 2018]. По определению ВОЗ, самопомощь подразумевает “способность индивидов, семей и сообществ, укреплять здоровье, осуществлять профилактику заболеваний, поддерживать здоровье и справляться с болезнями и недомоганиями самостоятельно или с помощью медицинских работников" [WHO, 2013: 15]. В этом контексте растет интерес не только к тому, как пациенты интерпретируют информацию, полученную от медицинских экспертов, но и к тому, какими дополнительными источниками пользуются для получения необходимой информации. Одним из таких источников выступает интернет. В интернете люди не только находят информацию о болезнях, с помощью которой они могут поставить себе диагноз, но и разные способы лечения или профилактики той или иной болезни, советы других пациентов и врачей. Кроме того, в ряде случаев интернет способен компенсировать недостатки профессиональной биомедицинской информации, адресованной некоему "усредненному" человеку. Даже получая профессиональную рекомендацию врача, многие люди склонны проверять информацию, задавая вопросы на интернет-форумах по поводу опыта других людей со сходными симптомами, по поводу побочных эффектов тех или иных препаратов. Возможности самоназначения лекарственных препаратов облегчаются широкой доступностью соответствующей информации в интернете. Такая информация черпается не только из специализированных информационных ресурсов, но и из разного рода форумов и сайтов социальных медиа, где люди имеют возможность обсудить свои проблемы с другими пользователями, находящимися в похожей ситуации или имеющими опыт употребления определенных лекарственных препаратов.

Использование интернета в практиках самоменеджмента здоровья является темой растущего интереса среди исследователей [Price et al., 2019; Chapman et al., 2019; Khanna et al., 2019; Allen et al., 2019; Middelaar et al., 2018; Sassenberg, Greving, 2016; Pehora 2015]. Есть отдельные работы, посвященные роли интернета в самостоятельном регулировании стресса и в его профилактике [Ebert, 2016; Zetterqvist et al., 2003], которые фокусируются в основном на оценке эффективности специально разработанных интернет-программ стресс-менеджмента. В то же время практически нет исследований, направленных на выявление того, как интернет-пользователи обсуждают медикаментозные способы управления стрессом. Известные нам исследования близкой тематики направлены на выяснение отношения людей к приему препаратов от бессонницы [Barbee et al., 2018; Gabe, Coveney, Williams, 2016; Moloney, Konrad, Zimmer, 2011], но в этих исследованиях не затрагивается аспект использования интернета для принятия решений о приеме лекарств. 
Цель исследования состоит в том, чтобы выявить типичные особенности самомедикализации стресса через изучение дискуссий интернет-пользователей, обсуждающих медикаментозные способы управления стрессом. Основные исследовательские вопросы: как обсуждается самодиагностика проблем здоровья, вызванных стрессом? Как пользователи описывают собственные тактики избавления от стресса? Какая роль в этом процессе отводится профессиональному медицинскому знанию и медикаментозным способам управления стрессом?

Сначала рассмотрим концепцию самомедикализации как теоретическую рамку для изучения медикаментозных способов управления стрессом и кратко опишем социальный контекст медикализации стресса в современном обществе. Затем раскроем ключевые паттерны употребления успокоительных препаратов, которые были идентифицированы в ходе качественного анализа комментариев пользователей, размещенных на отобранных интернет-ресурсах.

\section{Самомедикализация как социальный процесс}

Стресс и различные проблемы, связанные с ним, такие как раздражительность, бессонница и т. п., находятся на границе между медицинскими и немедицинскими определениями. Поэтому в отношении таких состояний ярко выражены как самомедикализация, когда человек сам диагностируют симптомы и наделяет их статусом болезни, требующей медикаментозного лечения, так и демедикализация, когда состояние здоровья, определяемое профессиональными медиками как болезнь, рассматривается человеком как не требующее вмешательства медицины.

В социологии понятие "медикализация" обозначает редукцию определенных, чаще всего социально нежелательных явлений к индивидуальным биологическим патологиям [Conrad, Waggoner 2017; Conrad, 2007; Михель, 2011]. 0 самомедикализации можно говорить в том случае, если человек интерпретирует с точки зрения медицины свое физическое или психическое состояние, которое сами врачи могут не рассматривать как требующее лечения. Стремление медикализировать собственное состояние имеет место в различных ситуациях. Человек может приписывать себе определенные болезни, даже не проконсультировавшись с врачом, или "находить" у себя заболевания, которых не находит врач, или стараться "вылечить" проблему, которую врач не считает нужным лечить [Fainzang, 2018: 36]. Обычно самомедикализация рассматривается как воспроизводство механизмов социального контроля на индивидуальном уровне. Хотя самомедикализация часто является следствием воспроизводства медицинского мнения, она может также вытекать из личного решения придать определенному состоянию медицинскую интерпретацию, чтобы прибегнуть к лечению. Понятия медикализации и самомедикализации часто используются также для описания специфической роли фармацевтических компаний, которые через рекламу и создание новых «рынков болезней" подталкивают потребителей к тому, чтобы самостоятельно управлять своим здоровьем, используя лекарственные препараты [Conrad, Leiter 2004].

Самомедикализация - самостоятельная интерпретация определенной проблемы как медицинской, - ведет к выработке соответствующей стратегии решения этой проблемы, включающей самообследование (self-examination), самодиагностику (self-diagnosis), самоназначение (self-prescription) и самоле- 
чение (self-medication) [Fainzang 2013]. В ходе самообследования как рутинного мониторинга своего здоровья определенные отклонения в физическом или психическом состоянии могут интерпретироваться как симптомы заболевания, требующего лечения. При этом они наделяются статусом симптома не автоматически, а в зависимости от разнообразных влияний и источников информации, формирующих интерпретацию. Такими источниками могут быть как опыт общения с врачами, друзьями, знакомыми, так и информация из литературы, СМИ или интернета. По мнению С. Файнцанг, сама идентификация симптома поднимает фундаментальный вопрос о том, что считается нормальным и патологическим в определенной культуре [ibid.: 495]. После того как человек удостоверится, что симптом является патологическим, принимается решение об обращении к врачу или о самостоятельном лечении. Последовательность этапов может быть и обратной, и тогда можно говорить о демедикализации состояния, которое раньше было медикализировано медицинскими профессионалами [Fainzang, 2013: 497; Conrad, Rondiniv 2016]. В этом случае человек отказывается от приема назначенного врачом лечения и начинает использовать доступные ему альтернативные способы решения проблемы.

\section{Социальный контекст медикализации стресса}

Идея о том, что быстрый темп современной жизни может приводить к различным проблемам со здоровьем, стала активно обсуждаться в XX веке. Хотя диагноз "нервное расстройство" использовался еще в 1920-х годах, бум использований этого понятия пришелся на 1940-е и 1950-е годы, когда оно вошло в повседневный лексикон, в котором фигурировало, скорее, не как болезнь, а как "немедицинский" феномен повседневной жизни, который может самостоятельно диагностироваться и не требует профессиональной помощи врачей [Barke, Fribush, Stearns, 2000: 575]. Со временем биологическая концепция стресса как неспецифического ответа организма на внешние раздражители, предложенная Г. Селье [Selye, 1938], вытеснила психологическую модель "нервного расстройства" и ранее существовавшие культурные референты эмоционального напряжения и неврастении. В 1970-х годах стресс стал рассматриваться как составляющая ряда медицинских диагнозов и как фактор риска возникновения определенных заболеваний. Произошла индивидуализация и медикализация стресса. Именно в таком контексте стресс стал объектом активного обсуждения в медицинских кругах, в СМИ, во множестве популярных книг о самопомощи и в повседневных разговорах [Watkins, 2013]. C 1970-х годов статьи в журналах давали советы, как самостоятельно справляться со стрессом и рассказывали читателям, что они сами могут контролировать свою реакцию на стресс, применяя методы релаксации. Все эти методы регулировать стресс были основаны на понятии самопомощи, а врачи пытались дать понять людям, что избавление от стресса - это индивидуальная задача каждого человека.

Индивидуализация проблемы стресса устранила необходимость критического рассмотрения социальных сил и структур, создающих стрессовые условия. Вместо этого возникли разнообразные коммерческие предприятия для обеспечения самоменеджмента стресса с широким диапазоном товаров и услуг. Фармацевтические 
компании стали массово производить лекарства от стресса, тревожности, нервных расстройств. Активно развивающийся фармацевтический рынок вместе с концепцией самопомощи повлиял на то, что люди все чаще начали использовать фармацевтические препараты как способ управления стрессом. Однако поскольку сами проблемы, связанные со стрессом, часто попадают в "серую зону" диагностики, то наблюдается двойственное отношение к применению лекарственных препаратов. С одной стороны, люди массово употребляют их, а с другой стороны, часто их прием считается проявлением слабости характера, недостатка силы воли, неумения справляться со своими эмоциями. Например, в исследовании отношения людей к употреблению снотворных препаратов был выявлен ряд “моральных репертуаров", определяющих отношение к этим препаратам и влияющих на решение об их употреблении [Gabe et al., 2016]. Согласно авторам исследования, человек, решающий вопрос о принятии медикаментов, руководствуется не только объективной информацией, но и собственными представлениями о "хорошем" и «плохом» способах лечения, обусловленными нормами, принятыми в обществе.

\section{Методы}

Для эмпирического анализа высказываний пользователей интернет-ресурсов, посвященных обсуждению приема успокоительных препаратов, были использованы данные, полученные в результате поиска в четырех наиболее популярных в России поисковых системах ("Google», "Яндекс", "Mail.ru», "Рамблер") ${ }^{11}$. Поиск велся по таким словосочетаниям, как "успокоительные форум", "стресс форум", "как справиться со стрессом", "лучшие успокоительные", "как справиться с нервным напряжением" и т. п. Анализировались результаты поиска, выданные на первых пяти страницах. Источники должны были также соответствовать минимальным критериям отбора: наличие форума или обсуждения; тематика обсуждения на сайте касается стресса или нервозных состояний; в обсуждении затрагивается хотя бы один фармацевтический препарат или БАД седативного действия; сайт не должен содержать рекламные материалы конкретного препарата.

В результате поиска по заданным словосочетаниям было выявлено 59 соответствующих критериям интернет-источников. Далее отбирались ресурсы, отвечающие следующим требованиям: ресурс должен содержать более 25 комментариев, последний комментарий не должен быть ранее 2013 г. В окончательный анализ было включено 13 интернет-источников, содержащих в общей сложности 762 комментария. Из них шесть представляли собой форумы и семь - обсуждения пользователей под статьями, посвященными применению фармацевтических препаратов для управления стрессом.

Кодирование данных осуществлялось в программе NVivo11 и сочетало дедуктивный и индуктивный подходы. На первом этапе производилось открытое кодирование отобранных текстов, в ходе которого текстовые данные были разбиты на смысловые фрагменты, каждому был приписан один или несколько кодов. Далее часть первичных кодов была сгруппирована в более широкие категории, выведенные из данных (индуктивные категории), а часть - приписана к кате-

\footnotetext{
${ }_{11}$ Рейтинг поисковых систем на 2017 год [Электронный ресурс] // Seo-auditor. URL: http://gs.seo-auditor.com.ru/ sep/2017/ (дата обращения: 01.04.2020).
} 
гориям, сформулированным до начала кодирования (дедуктивные категории). В результате кодирования было получено 17 категорий и 93 подкатегории, структурирующих содержание анализируемых текстов с точки зрения основных аспектов обсуждения медикаментозного управления стрессом.

\section{Результаты и интерпретация}

Первый этап самоменеджмента стресса - самодиагностика. Мы определили самодиагностику как интерпретацию определенных физических и психических состояний в качестве возможных симптомов заболевания, требующего лечения. В комментариях пользователи предпочитают описывать свое состояние сразу несколькими симптомами и определяют их через понятия "стресс", "депрессия", "нервное расстройство". "Диагнозы", основанные на повседневном знании, часто далеки от того, как они определяются в рамках профессиональной медицины. Показательно в этом отношении такое высказывание: “У меня обычно какое-то обострение депрессии происходит по весне и по осени и хорошо помогает трава пустырник". Примеры терминов, в которых пользователи описывают свое состояние, требующее приема успокоительных средств, представлены в таблице 1.

Таблица 1. Термины самодиагностики

\begin{tabular}{|c|c|c|}
\hline Симптомы & Примеры высказываний & $\begin{array}{c}\text { Количество } \\
\text { закодированных } \\
\text { фрагментов }\end{array}$ \\
\hline Нервозное состояние & $\begin{array}{l}\text { "Нервное состояние», "вся на нервах", "нервишки } \\
\text { шалят" }\end{array}$ & 32 \\
\hline Раздражительность & $\begin{array}{l}\text { "Очень многое из себя выводить стало", "все } \\
\text { начинает бесить" }\end{array}$ & 26 \\
\hline Бессонница & "Не хочется спать", "не могу заснуть" & 25 \\
\hline Стресс & "Стрессы бывают”, “стресс был просто жуткий” & 23 \\
\hline Усталость & $\begin{array}{l}\text { "Упадок сил”, “апатия", “совсем не хочу } \\
\text { ничего делать” }\end{array}$ & 14 \\
\hline Агрессия & "Злюсь на детей", "постоянно ору" & 13 \\
\hline Депрессия & “У меня депрессия”, “обострение депрессии” & 12 \\
\hline Чувство страха & "Страх перед...”, "боюсь, что все сделаю не так” & 11 \\
\hline Плаксивость & " Мокрые глаза", "чуть что - сразу плачу" & 9 \\
\hline Проблемы с давлением & "Давление скачет" & 8 \\
\hline Навязчивые мысли & $\begin{array}{l}\text { "Все время думаю, не могу заснуть”, "навязчивые } \\
\text { мысли” }\end{array}$ & 6 \\
\hline
\end{tabular}

В ходе анализа было выделено несколько типов стрессовых ситуаций, связанных с употреблением фармацевтических препаратов. Наиболее часто в обсуж- 
дениях пользователи упоминали бытовые проблемы, наличие маленьких детей, беременность, проблемы в семье, ссоры. Отдельно можно выделить тяжелые травмирующие ситуации, такие как развод, смерть близкого человека. Другая группа ситуативных контекстов включает проблемы, связанные с работой или учебой, которые могут сопровождаться как постоянной монотонной нагрузкой, так и перегрузками, авралами. Отдельную группу составляют ситуации, связанные со здоровьем (бессонница, болезнь, борьба с вредными привычками) и ситуации, вызывающие чувство страха (боязнь публичных выступлений, перелетов).

Относительно самоназначения и самолечения как составляющих самомедикализации стресса мы выделили три паттерна употребления успокоительных препаратов, различающиеся с точки зрения отношения к медикаментозному способу избавления от стресса, отношения к врачебной помощи и тактик, используемых для избавления от стресса. Далее рассмотрим подробно каждый из выделенных паттернов: самостоятельный выбор фармацевтического препарата как основного средства; самостоятельный выбор фармацевтического препарата как дополнительного средства; обращение к врачу для назначения лечения. Каждый из этих паттернов демонстрирует определенные социальные нормы, касающиеся как особенностей управления стрессом, так и отношения к профессиональной медицинской помощи.

"Надо соответствовать": самостоятельный выбор фармацевтического препарата как основного средства

Если резюмировать утверждения, характеризующие данный паттерн, то это будет выглядеть так: стресс - неотьемлемая часть повседневной жизни; врач не поможет; успокоительное - не лекарство, а средство привести себя в норму. Данная модель демонстрирует парадокс самомедикализации, когда проблема здоровья рассматривается как не слишком серьезная, чтобы обращаться к врачу, однако требующая приема лекарственных препаратов. Пользователи с легкостью ставят себе диагноз и обращаются за советом к другим пользователям: «Здравствуйте. У меня после родов повышения нервозность. Посоветуйте, пожалуйста, какие-нибудь таблетки". Отношение к стрессу как к незначительной, распространенной и несерьезной проблеме влияет на то, что люди сами назначают себе лекарственные препараты и считают, что нет необходимости обращаться к врачу: "На фоне этих вечных детских ссор становлюсь раздражительной. К врачу идти с таким пустяком не хочется, а пропить успокоительное не помешало бы", "Нервное напряжение - это вполне типично для многих".

Общая черта высказываний, объединенных в рамках этой модели,- -стремление регулировать свое состояние фармацевтическими препаратами и в то же время лишний раз не обращаться к врачу: “Я за прием препаратов во время депрессии, но лишь в пределах разумного, никаких транквилизаторов и т. д. К врачу, правда, тоже не хожу, обхожусь легкими успокоительными...". К врачебной помощи приверженцы этой модели относятся скорее отрицательно, что объясняют несколькими факторами. Во-первых, организационные трудности посещения врачей (например, наличие очередей): “Не дожидаться момента похода в поликлинику и выписки рецепта". Во-вторых, наличие сомнений в профессионализ- 
ме врачей ("Наши врачи самые опасные. В институте не учатся"), в их честности и бескорыстности ("Но врачу ныне нужны пациенты. Излечить - значит потерять доход"), в качестве оказываемой помощи ("Кроме того, многие врачи назначают сильнодействующие препараты, а я их принимать не хочу").

Важная особенность этой модели поведения - доверие фармацевтическим препаратам и медикаментозным способам избавления от стресса. Такие пользователи рассматривают фармацевтические препараты как необходимое условие выживания в современном мире, позволяющее получить быстрый эффект: “Книжки, чай, и любимая музыка это все очень хорошо и даже работает, но когда у вас есть на это время. Я работаю в режиме постоянного стресса, на книжки и музыку времени нет". Цель употребления препаратов состоит в том, чтобы быстро привести себя в форму и соответствовать требованиям, предъявляемым быстрым темпом современной жизни: повысить стрессоустойчивость (“мне работать нужно, и в то же время стрессоустойчивость поднять"), успокоиться и попытаться заснуть ("для лучшего состояния, сна хорошего, да и просто успокоить нервы после тяжелого рабочего дня"), привести себя в "нормальное состояние" (“хороший способ привести нервы в порядок"), для быстрого, срочного успокоения («нужно быстро привести нервы в порядок"), перестать нервничать ("для храбрости, а то каждый раз на совещаниях я начинаю волноваться"). Некоторые сторонники этой модели считают, что препараты успокоительного действия - это не только спасение от стрессов, но и своего рода профилактика негативных последствий стрессовых ситуаций. Рассматривая нервное напряжение как причину более серьезных болезней, эти пользователи принимают успокоительные в качестве необходимой помощи своему здоровью: "Нервы нужно обязательно успокаивать, потому что все болезни от нервов и это правда. И сильно отражается на внешнем виде. И стареешь быстрее".

Сторонники данной модели описывают собственные практики приема препаратов, часто презентуя себя как потребителей, проявляющих разумную осторожность во избежание негативных побочных эффектов. Пользователи сообщают, что они самостоятельно регулируют прием препарата или его дозировку по своему самочувствию. При этом лишь в двух случаях они упомянули, что препарат нужно принимать по инструкции. Например, один пользователь для предостережения других сообщает о негативном опыте самостоятельного решения о прекращении приема препарата, вопреки инструкции: "Не успел даже до конца высосать упаковку, как нужда в нем совершенно отпала - все пришло в полнейший порядок (и сон, и сердце, и прочее). Пить его резко бросил, и три дня от этого болела голова, сосуды в мозгу резко сузились (он же сосудорасширяющий еще), так что даже случилось временное выпадение небольших участков зрения (смотришь на слово, а последние буквы не видишь!). Это и само по себе неприятно, и может закончиться даже микроинсультом". Интересно, что даже при неудачном опыте самоназначения препаратов эти пользователи все-таки стремятся продолжить практики самолечения и обращаются в интернет за советом: «Попробовал пить новопассит - без результата, персен тоже не подействовал, а при употреблении нитроглицирина появляется ужасная головная боль в придачу. Что пить, подскажите?". Интересно, что процесс приема лекарств некоторые пользователи воспринимают как способ избавления от нервного напряжения: “Сам факт принятия 
препаратов дисциплинирует мозги. Создается ощущение, что становится все легче и легче... Систематический прием препаратов сам по себе успокаивает".

Пользователи, самостоятельно назначающие себе успокоительные препараты, не прочь поэкспериментировать, часто они сообщают, что пробуют препараты разных фирм, разного состава и разной степени воздействия на организм: “Очень нервная я, часто стрессы бывают. Лучше всего помог грандаксин, но пошла одышка, афобазол, глицин, фенибут, персен, новопассит не помогли. Сейчас куплю адаптол или тенотен. Настойки, кроме корвалола, не очень помогают"; "Есть масса средств, отпускаемых без рецепта, всех не перепробуешь". Среди участников проанализированных интернет-ресурсов есть и отрицательно относящиеся к лекарствам, но отказаться от них они уже не могут, так как убеждены, что без лекарств не смогут жить нормально: «Последнее время на успокоительных живу. Разорилась уже на них. И без них не могу. Перепробовала все что стоит в пределах 300 рублей, на более дорогие боюсь не потяну. Как дальше жить? Спать не могу, спокойно реагировать на малейшие раздражители не могу. Уже стала зависима от таблеток".

В терминологии моральных репертуаров [Gabe et al., 2016] наиболее яркий тип потребителя лекарств, представленных данной моделью,- это “зависимый пациент". Такой пациент осознает, что он не может нормально жить или справляться со стрессом без лекарственных препаратов, и оправдывает потребление препаратов тем, что ему это необходимо. Хотя такой пациент и задумывается о последствиях, но готов принимать лекарство при любом возможном случае, когда чувствует себя некомфортно или когда надо срочно решить проблему.

"Взять себя в руки": употребление фармацевтических препаратов как дополнительный способ избавления от стресса

"Человек - часть природы", "стресс - результат неправильной организации жизни", "лекарства — крайняя мера" - такие высказывания резюмируют главные черты второго из выделенных нами паттернов употребления успокоительных препаратов. Суть его состоит в том, что лекарство принимается в качестве дополнительного средства, когда были опробованы немедицинские методы - от попыток "взять себя в руки" до разного рода расслабляющих практик.

Для пользователей, рассматривающих фармацевтические препараты как дополнительный способ борьбы с последствиями стресса, важно сначала самостоятельно справиться с проблемой, используя немедицинские ресурсы. Только в если справиться самостоятельно не получается, они обращаются к лекарствам. У пользователей, придерживающихся данной модели, достаточно много информации о здоровье в целом, о причинах своего состояния, о том, как лучше выстраивать свое поведение. Правильная организация своей жизни рассматривается такими пользователями как ключевое условие избавления от негативных реакций на стрессовые ситуации: «Нельзя пойти против природы и спать меньшее количество часов, чем это необходимо для твоего организма".

Альтернативные способы избавления от стресса, о которых пишут пользователи, разнообразны: музыка, хобби, спорт, чтение, прогулки, общение с друзьями и пр. Как показывает анализ, к данным способам пользователи обращаются, когда ситуация не слишком серьезна и не является экстренной, а стресс воспринимает- 
ся, скорее, не как неизбежный спутник повседневной жизни, а как следствие ее неправильной организации. Для таких пользователей прием фармацевтических препаратов становится дополнительным способом, когда нелекарственный метод перестает работать или требует много времени: “В случае, когда совсем ничего не спасает, плюс наваливаются на работе напряженные периоды, то добавляю курс препарата, чтоб мозг нормально функционировал, и чтоб депрессия не навалила окончательно".

Целью употребления препаратов в данном случае является дополнительная помощь, когда нет возможности справиться со стрессом другими методами: "когда аврал на работе, еще дополнительно пью хорошее успокоительное». Наиболее часто пользователи, придерживающиеся данной модели, упоминают гомеопатические препараты и лекарственные препараты натурального состава, так как, по их мнению, они наиболее безопасны: "Я-за растительные успокоительные (мята, мелисса, пион), много вариантов уже перепробовала"; "Я обычно, если уснуть не могу или перенервничаю, первым делом пробую заварить травки, особенно нравится мне мятный чай".

Если в первой модели основной мотив употребления лекарства состоит в том, чтобы привести себя в норму и соответствовать предъявляемым обществом требованиям, то во второй модели основным мотивом является забота о здоровье. Для реализации такой модели кроме "силы воли" важно наличие временных и информационных ресурсов для соответствующей организации жизни. Портрет пациента в терминах моральных репертуаров может быть описан, как промежуточный между "ответственным пациентом" и "пациентом, отказавшимся от лечения". Если для "ответственного пациента" применение лекарств всегда подвергается критическому изучению с точки зрения возможных негативных эффектов, то «пациент, отказавшийся от лечения", склонен воспринимать любой недуг как способ проверки своей моральной силы, способности справиться самостоятельно, без применения лекарственных средств. Поэтому в данном случае часто наблюдается демедикализация стресса как состояния, которое обусловлено не столько биологическими, сколько социальными причинами, такими как неправильная организация жизни и взаимодействия с людьми.

"Не занимайтесь самолечением, оно вам все равно не поможет": употребление фармацевтических препаратов по назначению врача

В данном паттерне наиболее четко прослеживаются такие особенности, как экстраординарность стрессовой ситуации, тяжесть состояния, доверие медицине и врачам. Обращение к специалисту - свидетельство восприятия своего состояния именно как болезни и как проблемы, с которой нет возможности справиться самостоятельно. В комментариях пользователей упоминаются следующие эксперты: “врач» (без указания специальности), "невролог”, "психотерапевт", "психиатр", "эндокринолог", "кардиолог", "Психолог". Часто причиной, заставляющей людей обращаться к помощи специалистов, становятся стрессовые ситуации, выходящие за рамки повседневной рутины, например, смерть близкого человека, развод, когда нет возможности самим справиться с последствиями стрессовой ситуации. Также упоминаются проблемы с работой и семьей: “..двое детей двойняшек только пошли в сад, болеют постоянно. У меня уже кругом голова от всего. На работе 
не особо приветствуют, что ухожу на больничный. Очень переживаю по этому поводу"; "Жутко устала на работе, почти впала в депрессию".

Большинство пользователей, обращавшихся к специалистам, советуют другим пользователям не заниматься самолечением: “Друзья, вам никто не рассказывал, что самолечением опасно заниматься? Сходите к невропатологу, а лучше с несколькими специалистами проконсультироваться"; "При подобных ситуациях не бойтесь даже психиатра, не занимайтесь самолечением, оно вам все равно не поможет!!!". В то же время некоторые пользователи демонстрируют критическое отношение к врачебной помощи, указывая на опасность назначения сильнодействующих препаратов: «Психотропы ламают жизни, притом серьезно ломают. Мне передоз сделали, вот теперь и мучаюсь, Спасибо врачам!». Описываемые проблемы показывают, что использование профессиональной медицинской помощи не избавляет от сомнений в правильности назначенного лечения. Поэтому пользователи, обращавшиеся к врачам, обсуждают в интернете фармацевтические препараты для получения информации от других об опыте употребления тех или иных препаратов. "Психотерапевт прописал антидепрессант, но я не стала его пить. Боюсь реакции организма. А психолог сказал, что это проблемы, которые залегли с годами глубоко в подсознании. Вот и мучаюсь периодически. То Афобазол, то Корвалол, то Валериану. Во время приступа пью таблетку Но-шпы и 2-3 таблетки Валерианы".

Пользователи дают друг другу советы о необходимости соблюдения врачебных рекомендаций и приводят примеры того, как несоблюдение режима приема может принести вред. “Врач <...> прописал лекарство, но предупредил, что пропить его надо столько, сколько он рекомендует, ни в коем случае не бросать раньше. Она начала пить лекарство, почувствовала, что ей стало хорошо, т. е. вернулась к своему прежнему состоянию, и перестала пить таблетки, не пройдя и половины курса. В итоге все ужасы вернулись к ней обратно, и она снова отправилась к психиатру". Сторонники этой модели подчеркивают важность обследования перед применением лекарств: “К врачу все-таки сходите. Принимать сильные препараты или нет, решение останется за вами, а вот какие пройти анализы-лучше врача вам никто не подскажет". Пользователи советуют также обращаться к врачам в ситуациях, когда необходимо учитывать совместимость препаратов и более серьезно относиться к побочным эффектам: «По поводу успокоительных: поскольку у Вас диабет, Вам лучше поговорить с лечащим врачом, обязательно!".

Одной из самых часто обсуждаемых причин обращения к специалисту является неудачный опыт самолечения: “Когда уже наглоталась, целую кучу разных препаратов, большинство из них в таблетках, и после того, как появились расстройства кишечника, решила обратиться к специалистам". В качестве другой причины обращения к врачу называется боязнь перед последствиями самолечения: «Мне кажется, что не стоит в таком случае уповать на препараты. Потом только в зависимость от них попадете. Обратитесь к невропатологу". Некоторые пользователи пишут, что инициатива обращения к специалистам принадлежала не им, а родственникам или знакомым, которые дают соответствующий совет или сами организуют посещение врач: «Муж больше этого терпеть не мог, записал меня к врачу".

Для данного паттерна наиболее характерен моральный репертуар «пациент, заслуживающий лечения". Такие пациенты трактуют любые проблемы своего 
физического состояния в первую очередь с медицинской точки зрения, представляя себя нуждающимися в лекарстве, и полагаются на препараты, назначенные врачом. Однако они также стремятся получить дополнительную информацию об эффективности приема соответствующих препаратов, обращаясь с этой целью на интернет-форумы. Это свидетельствует о том, что к врачебным назначениям они относятся с некоторой долей опасений, чаще всего касающихся употребления сильнодействующих препаратов.

\section{Заключение}

Выделенные в ходе исследования паттерны употребления фармацевтических препаратов различаются по степени самомедикализации стресса и позволяют понять, насколько люди, которых затронула данная проблема, склонны решать ее самостоятельно с помощью медикаментов и советов интернет-пользователей, и в каких ситуациях полагаются на профессиональную медицинскую помощь.

В паттерне "самостоятельное употребление препарата без консультации с врачом" наиболее ярко проявился парадокс самомедикализации, когда состояние, не рассматривающееся как болезнь, приводит к решению о необходимости приема лекарственных препаратов для того, чтобы соответствовать определенным нормативным требованиям, предъявляемым обществом, например, со стороны рынка труда или домашних обязанностей. Стремление быстро привести себя в форму с помощью медикаментов связано со стремлением решить не столько проблему здоровья, сколько проблему соответствия социальной роли, выполняемой индивидом. Такие люди обращаются к интернет-ресурсам в первую очередь для того, чтобы проконсультироваться с другими пользователями или поделиться своим опытом приема разнообразных препаратов.

Паттерн «употребление препаратов как дополнительный способ избавления от стресса" демонстрирует тенденцию демедикализации, когда определенные физические проблемы рассматриваются как следствие неправильной организации жизни, а не как следствие сбоев в работе организма, которые можно исправить приемом лекарств. В таких случаях прием фармацевтических препаратов становится дополнительным методом, только если усилия по правильной организации жизни не приносят желаемых результатов или при возникновении экстремальных нагрузок. Пользователи, демонстрирующие данный паттерн поведения, с удовольствием делятся в интернете советами по “правильной" организации жизни.

Паттерн "употребление препаратов по назначению врача" характерен для пользователей, которые уповают на профессиональную медицинскую помощь, причинами чего могут быть серьезные проблемы со здоровьем, экстремальные стрессовые ситуации или неудачный опыт самостоятельного лечения. Несмотря на большее доверие официальной медицине, чем в двух предыдущих случаях, такие пользователи, тем не менее, обращаются к интернет-источникам, чтобы узнать об опыте других пользователей и оценить адекватность врачебных назначений.

Необходимо упомянуть некоторые ограничения нашего исследования. Поскольку мы полагались на метод анализа текстов, опубликованных интернетпользователями, у нас не было возможности задать дополнительные вопросы и определить, насколько выделенные паттерны употребления препаратов связаны 
с более широким социальным контекстом и с характеристиками самих пользователей, а также выяснить, какова распространенность того или иного паттерна в определенных социальных контекстах. Тем не менее можно предположить, что выделенные паттерны употребления фармацевтических препаратов могут быть выявлены и для других проблем здоровья, что требует проверки в дальнейших исследованиях.

\section{Список литературы (References)}

Бухтияров И.В. Профессиональный стресс в результате сменного труда как фактор риска нарушения здоровья работников // Анализ риска здоровью. 2016. № 3. C. $110-121$.

Bukhtiyarov I. V. (2016) Occupational stress as a result of shift work as a risk factor for workers' health problems. Health Risk Analysis. No. 3. P. 110-121. (In Russ.)

Давыдова И.А., Козьмина Я.Я. Профессиональный стресс и удовлетворенность работой преподавателей российских вузов // Вопросы образования. 2014. № 4. C. $169-183$.

Davydova I. A., Kozmina Ya. Ya. (2014) Professional stress and satisfaction with the work of teachers in Russian universities. Educational Issues. No. 4. P. 169-183. (In Russ.)

Зотова О. М., Зотов В. В. Информационные перегрузки как фактор стресса студентов вузов // Человек и его здоровье. 2015. № 4. С. 108-115.

Zotova O. M., Zotov V. V. (2015) Information overload as a stress factor for university students. Human and Health. No. 4. P. 108-115. (In Russ.)

Имамгалиева Л. А. Социологический анализ влияния стресса на учебное поведение студентов // Вестник Тамбовского университета. 2017. № 2. С. 73-76.

Imamgalieva L. A. (2017) A sociological analysis of the effect of stress on students' academic behavior. Journal of the Bulletin of the Tambov University. No. 2. P. 73-76. (In Russ.)

Короленко А. В. Стресс как фактор риска здоровья населения и распространения вредных привычек // Здоровье человека, теория и методика физической культуры и спорта. 2019. № 1. С. 3-26.

Korolenko A. V. (2019) Stress as a risk factor for public health and the spread of bad habits. Human Health, Theory and Methods of Physical Culture and Sports. No. 1. P. 3-26. (In Russ.)

Михель Д. В. Медикализация как социальный феномен // Вестник Саратовского государственного технического университета. 2011. № 4 (2). С. 256-263.

Michel D. V. (2011) Medicalization as a social phenomenon. Bulletin of Saratov state technical University. No. 4 (2). P. 256-263. (In Russ.)

Сабадаш А. Г. Стратегии преодоления стрессов студентами вузов // Общество: социология, психология, педагогика. 2016. № 5. С. 44-46. 
Sabadash A. G. (2016) Stress Management Strategies for University Students. Society: Sociology, Psychology, Pedagogy. No. 5. P. 44-46. (In Russ.)

Толпыгина С.Н., Марцевич С. Ю., Концевая А. В., Драпкина О. М. Ответственное самолечение - основополагающие принципы и место в современной системе здравоохранения // Рациональная фармакотерапия в кардиологии. 2018. Т. 14. № 1. C. 101-110. https://doi.org/10.20996/1819-6446-2018-14-1-101-110.

Tolpygina S. N., Martsevich S. Y., Kontsevaya A. V., Drapkina O. M. (2018) Responsible Self-Care - the Fundamental Principles and Place in the Modern Russian Healthcare System. Rational Pharmacotherapy in Cardiology. Vol. 14. No. 1. P. 101-110. (In Russ.) https://doi.org/10.20996/1819-6446-2018-14-1-101-110.

Шафиркин А.В. Влияние социального стресса и психо-эмоциональной напряженности на здоровье мужчин трудоспособного возраста в России // Вестник Российского государственного медицинского университета. 2013. № 5-6. С. 27-34.

Shafirkin A. V. (2013) The influence of social stress and psycho-emotional tension on the health of working-age men in Russia. Bulletin of the Russian State Medical University. No. 5-6. P. $27-34$.

Allen C., Vassilev I., Lin S. X., Culliford D., Rogers A. (2019) The contribution of internet use in personal networks of support for long-term condition self-management. Chronic illness. Vol. 15. No. 3. P. 220-235. https://doi.org/10.1177/1742395318759588.

Barke M., Fribush R., Stearns P. N. (2000) Nervous Breakdown in 20th-Century American Culture. Journal of Social History. Vol. 33. No. 3. P. 565-584.

Barbee H., Moloney M. E., Konrad T.R. (2018) Selling slumber: American neoliberalism and the medicalization of sleeplessness. Sociology Compass. Vol. 12. No. 10. e12622. P. 1-16.

Chapman L., Brooks C., Lawson J., Russel, C., Adams, J. (2019) Accessibility of online self-management support websites for people with osteoarthritis: A text content analysis. Chronic IIIness. Vol. 15. No. 1. P. 27-40. https://doi.org/10.1177/ 1742395317746471.

Conrad P., Leiter V. (2004) Medicalization, Markets and Consumers. Journal of Health and Social Behavior. Vol. 45 (Extra Issue). P. 158-176.

Conrad P. (2007) The medicalization of society: On the transformation of human conditions into treatable disorders. Baltimore, MD, US: Johns Hopkins University Press.

Conrad P., Rondiniv A. The internet and medicalization: Reshaping the global body and illness. In: Culture, bodies and the sociology of health. Ed. By E. Ettorre. Routledge, 2016. 115-128.

Conrad P., Waggoner M. (2017) Anticipatory medicalization: predisposition, prediction, and the expansion of medicalized conditions. In: Medical Ethics, Prediction, and Prognosis Interdisciplinary Perspectives. Routledge. P. 95-103. 
Ebert D. D. et al. (2016) Self-guided internet-based and mobile-based stress management for employees: results of a randomised controlled trial. Occupational and Environmental Medicine. Vol. 73. No. 5. P. 315-323.

Fainzang S. (2018) A deviant diagnosis? Doctors faced with a Patient's diagnostic work. In: Diagnostic Fluidity: Working with Uncertain and Mutability. Tarragona, URV Publicacions. P. 35-54.

Fainzang S. (2013) The Other Side of Medicalization: Self-Medicalization and SelfMedication. Vol. 37. No. 3. P. 488-504. Cult Med Psychiatry. P. 488-454. https:// www.doi.org/10.1007/s11013-013-9330-2.

Gabe J., Coveney C. M., Williams S. J. (2016) Prescriptions and proscriptions: moralising sleep medicines. Sociology of Health \& IIIness. Vol. 38. No. 4. P. 627-644.

Glei D. A., Goldman N., Shkolnikov V. M., Jdanov D., Shkolnikova M., Vaupel J. W., Weinstein M. (2013) Perceived Stress and Biological Risk: Is the Link stronger in Russians than in Taiwanese and Americans? Stress. The International Journal on the Biology of Stress. Vol. 16. No 4. P. 411-420.

Grady P. A., Gough L. L. (2014) Self-management: a comprehensive approach to management of chronic conditions. American Journal of Public Health. Vol. 8. No. 104. P. $25-31$.

Khanna D., Serrano J., Berrocal V., Silver R., Cuencas P., Newbill S., Battyany J., Maxwell C., Alore M., Dyas L., Riggs R., Connolly K., Kellner S., Fisher J., Bush E., Sachdeva A., Evnin L., Raisch D., Poole J. (2019) Randomized Controlled Trial to Evaluate an Internet-Based Self-Management Program in Systemic Sclerosis. Arthritis Care and Research. Vol. 71. No. 3. P. 435-447. https://www.doi.org/10.1002/acr.23595.

Leventhal H., Phillips L. A., Burns E. (2016) The Common-Sense Model of SelfRegulation (CSM): A dynamic framework for understanding illness self-management. Journal of behavioral medicine. Vol. 39. No. 6. P. 935-946.

Moloney M. E., Konrad T. R., Zimmer C. R. (2011) The medicalization of sleeplessness: a public health concern. American journal of public health. Vol. 101. No. 8. P. 1429-1433.

Pehora C., Gajaria N., Stoute M., Fracassa S., Serebale-O'Sullivan R., Matava C.T. (2015) Are parents getting it right? A survey of parents' internet use for children's health care information. Interactive journal of medical research. Vol. 4. No. 2. e12. https://www.doi.org/10.2196/ijmr.3790.

Price A., Vasanthan L., Clarke M., Liew S. M., Brice A., Burls A. (2019) SMOOTH (SelfManagement of Open Online Trials in Health) analysis found improvements were needed for reporting methods of internet-based trials. Journal of Clinical Epidemiology. Vol. 105. P. 27-39. https://www.doi.org/10.1016/j.jclinepi.2018.08.017.

Sassenberg K., Greving H. (2016) Internet searching about disease elicits a positive perception of own health when severity of illness is high: a longitudinal questionnaire study. Journal of medical Internet research. Vol. 18. No. 3. e56. P. 1-11. 
Selye H. (1938) Adaptation Energy. Nature. Vol.141. No. 3577. P.926. https://www.doi.org/ 10.1038/141926a0.

Middelaar T. van, Beishuizen C.R.L., Guillemont J., Richard E., van Charante E. P.M. Engaging older people in an internet platform for cardiovascular risk self-management: a qualitative study among Dutch HATICE participants. BMJ Open. 2018. Vol. 8. No 1. https://www.doi.org/10.1136/bmjopen-2017-019683.

Väänänen A., Murray M., Kuokkanen A. (2014) The growth and the stagnation of work stress. Publication trends and scientific representations 1960-2011. History of the Human Sciences. Vol. 27. No 4. P. 116-138.

Watkins E. S. (2013) An Investigation into the Medicalization of Stress in the Twentieth Century. Medicine Studies. Vol. 4. No. 1-4. P. 29-36. https://www.doi.org/10.1007/ s12376-013-0082-7.

WHO. Self Care for Health. A Handbook for Community Health Workers \& Volunteers. (2013) World Health Organization. URL: https://apps.who.int/iris/bitstream/handle/ 10665/205887/B5084. pdf?sequence=1\&isAllowed=y (accessed: 05.03.2020).

Zetterqvist K., Maanmies J., Ström L., Andersson G. Randomized controlled trial of internet-based stress management. Cognitive Behaviour Therapy. 2003. Vol. 32. No. 3. P. $151-160$. 